\title{
Nanomole per Liter per Gram
}

National Cancer Institute

\section{Source}

National Cancer Institute. Nanomole per Liter per Gram. NCI Thesaurus. Code C119467.

A unit of concentration equal to nanomoles per liter, divided by grams. 